\title{
Rising cancer rates in the Arab World: now is the time for action
}

Mostafa Ahmed Arafa, ${ }^{1,3}$ Danny Munther Rabah ${ }^{1,2}$ and Karim Hamda Farhat ${ }^{1}$

${ }^{1}$ Cancer Research Chair, College of Medicine, King Saud University, Riyadh, Saudi Arabia. ${ }^{2}$ Surgery Department, College of Medicine, King Saud University, Riyadh, Saudi Arabia. ${ }^{3}$ High Institute of Public Health, Alexandria University, Alexandria, Egypt. (Correspondence to: Karim Hamda Farhat: Kfarhat@ksu.edu.sa)

Citation: Arafa MA; Rabah DM; Farhat KH. Rising cancer rates in the Arab World: now is the time for action. East Mediterr Health J. 2020;26(6):638640. https://doi.org/10.26719/emhj.20.073

Received: 26/04/20 ; accepted: 19/05/20

Copyright (C) World Health Organization (WHO) 2020. Open Access. Some rights reserved. This work is available under the CC BY-NC-SA 3.0 IGO license (https://creativecommons.org/licenses/by-nc-sa/3.o/igo).

\section{Introduction}

Cancer is a universal public health problem. It is a leading cause of death worldwide, accounting for an estimated 9.6 million deaths in 2018. More than half of all cancers $(56.8 \%)$ and cancer deaths $(64.9 \%)$ in 2012 occurred in lower income regions of the world, and these proportions will increase further by $2025(1,2)$. Among Arabs, cancer is growing at an alarming pace. The Gulf States and the Eastern Mediterranean Region (EMR) countries show a disturbing rise in the number of cancer patients, Long-term projections show that, by 2030 there would be a 1.8 fold increase in cancer incidence (Table 1). While $80 \%$ of countries in the Region have national cancer control policies, only $45 \%$ of these programmes are operational (3). In addition, the total research output remains low, particularly studies relating to preventative cancer control policies (4).

The 2016 report by the Statistical, Economic and Social Research and Training Centre for Islamic Countries (5), indicates that more than one and half million new cases of cancer were diagnosed in 2012 (5), and that Islamic countries accounted for $11 \%$ of cancer cases globally and $17 \%$ in low and middle-income countries (5). Breast cancer is by far the most prevalent cancer, followed by lung cancer, cervical cancer, colorectal cancer, and prostate cancer. In absolute numbers, cancers in Islamic Countries caused 1.02 million deaths in 2012, accounting for $17.4 \%$ of the total deaths in low and middle-income countries and $12 \%$ of the global cancer deaths (5) (Table 2).

The age standardized incidence rate of the top five cancers in Islamic countries, in addition to the liver and bladder cancer in Egypt, has increased during the past 10 years (6-9). Lung cancer is also the most common cancer affecting males in the Gulf States as well as Algeria, Jordan, Lebanon, Palestinian Territories, Morocco and Tunisia. It is predicted that there will be 29576 new cases of lung cancer in 2020, up from 16596 in 2008 (10). Such increased burden is ascribed to increased cigarette smoking and other tobacco products among young adults (11).

Meanwhile, the general incidence of cancer in Lebanon is among the highest in the EMR and is expected to remain as such over the coming decade, where the number of cases has been increasing by $4-5 \%$ annually $(9,12)$. While cancer etiology is multifactorial, a set of known risk factors have been hypothesized as contributing to the dynamics of cancer epidemiology (13). While only $10-30 \%$ of all cancers are due to genetic predisposition, lifestyle factors such as smoking, more use of transport and less exercise, unhealthy foods and alcohol consumption have contributed to $70-90 \%$ of cancer cases, accentuated by emotional stress and environmental and air pollution in the Arab World (14).

The prevalence of obesity in adults in the EMR is very high, particularly among women, and the prevalence of diabetes mellitus parallels that of obesity. Increases in body mass indexes (BMIs) is expected to increase colorectal, liver and gastric carcinoma, particularly among males, where BMI has a stronger effect on cancer incidence in males than in females, as observed in some counties such as Lebanon (15).

The paucity of cancer research in Arab populations is a loss to the academic community. The variety of environments, lifestyles and ethnic differences provides a spectrum of opportunities, which, if studied adequately, would lead to a much more rapid increase in our understanding of the causes of cancer and our ability to control it. While breast cancer screening programmes

Table 1 Incidence, mortality and prevalence of cancer globally and in the Eastern Mediterranean Region (in 2002 and projection in 2030) (21)

\begin{tabular}{|c|c|c|c|c|}
\hline & World 2002 & World 2030 & EMR 2002 & EMR 2030 \\
\hline Population census & 6229629168 & 8206457382 & 492721000 & 649074572 \\
\hline Absolute incidence & 11000000 & 27000000 & 529000 & 1953714 \\
\hline Deaths & 7000000 & 17000000 & 272000 & 1003145 \\
\hline Prevalence & 25000000 & 75000000 & 1017441 & 3758142 \\
\hline
\end{tabular}




\begin{tabular}{|c|c|c|c|}
\hline \multicolumn{2}{|c|}{ Men } & \multicolumn{2}{|c|}{ Women } \\
\hline Site & $\begin{array}{l}\text { Percentage from the total } \\
\text { cancers }\end{array}$ & Site & $\begin{array}{l}\text { Percentage from the total } \\
\text { cancers }\end{array}$ \\
\hline Lung cancer & $23.9 \%$ & Breast cancer & $49.9 \%$ \\
\hline Prostate cancer & $17 \%$ & Cervical cancer & $18 \%$ \\
\hline Colorectal cancer & $12.2 \%$ & Colorectal cancer & $7.3 \%$ \\
\hline Liver cancer & $10.9 \%$ & Ovarian cancer & $5 \%$ \\
\hline Urinary bladder cancer & $7.3 \%$ & Stomach cancer & $2.5 \%$ \\
\hline Total \% of all cancers & $71.3 \%$ & & \\
\hline
\end{tabular}

are the only adopted programme in most Arab countries, an earlier survey showed a very low rates of breast cancer screening adherence among women in Saudi Arabia, a country with free health services, which indicates that social and psychological barriers to breast cancer screening exist (16).

\section{The World Health Organization Cancer Control Strategy}

According to the World Health Organization (WHO), cancer has become a health priority in the EMR. The aim of the WHO Cancer Control Strategy is to strengthen and accelerate the translation of cancer control knowledge into public health action. The focus is placed on the reduction of cancer cases and the improvement of the quality of life of cancer patients and their families.

However, the largest obstacle to tackling the global cancer incidence and mortality rate in the EMR is the lack of accurate and well-defined data, including a lack of a clear and well-documented public health policy for all noncommunicable diseases, including cancer; and lack of political support to develop legislation and regulation to build up and enhance the viability of cancer registries (17).

While most of Arab countries have population-based cancer registries, not all cancers are well documented and data on cancer mortality are limited; for example, no solid evidence exists regarding the true prevalence and incidence of oral cancers in most Arab countries due to the lack of population-based studies (18). In addition, according to the latest cancer incidence report from the Gulf Centre for Cancer Control and Prevention (19), and other studies (20), most cancers among nationals from the Gulf States were diagnosed at late stages and affected a much younger population. A variety of factors are at play, including geographic barriers that make it difficult to access care, lack of medical infrastructure and trained professionals to provide quality care, as well as a lack of awareness or insufficient understanding of the biology of cancer.

\section{Plan of action in the Islamic and Arab World}

Prevention and control measures should be targeting modifiable risk factors through primary and secondary prevention, early detection and protection of the population's health and well-being. This could be approached through the adoption of national screening programmes for the most prevalent cancers found in Arab countries, or through shared decision-making policy, where patients are supported to consider options and achieve informed preferences, e.g. shared decision-making practice for early detection of cancer prostate. Ultimately, there is a need for a public health approach, improvement of regional and national cancer registries, as well as health education campaigns addressing the barriers to cancer screening.

\section{References}

1. Bray F, Ferlay J, Soerjomataram I, Siegel RL, Jemal A. Global cancer statistics 2018: GLOBOCAN estimates of incidence and mortality worldwide for 36 cancer in 185 countries. CA Cancer J Clin 2018 Nov;68(6):394-424. doi: 10.3322/caac.21492.

2. World Health Organization. Cancer - fact sheet. Geneva: World Health Organization; 2018 (http://www.who.int/news-room/ fact-sheets/detail/cancer).

3. World Health Organization. Cancer control: a global snapshot in 2015. Geneva: World Health Organization; 2015 (www.who.int/ cancer/Cancer_Control_Snapshot_in_2015.pdf?ua=1).

4. Hamadeh RR, Borgan SM, Sibai AM. A review of publications from seven countries between 2000-2013. Sultan Qaboos Univ Med J. 2017 May;17(2):e147-e154.

5. OIC countries account for 11\% of the world cancer cases. Arab News, 18 March 2018 (http://www.arabnews.com/node/963066/ world. March 2018).

6. Al-Gahtani S, Abozaid S, Al-Nami E, Merie L, Al-Yousef A, Shoukri MM. Breast and ovarian cancer in young women of the Arabian Gulf Region: relationship to age. Open J Epidemiol. 2016;6:173-182. 
7. Ibrahim AS, Khaled HM, Mikhail NNH, Baraka H, Kamel H. Cancer Incidence in Egypt: results of the national population-based cancer registry program. J Cancer Epidemiol. 2014;2014:1-18 doi:10.1155/2014/437971

8. Abdel-Razeq H, Attiga F, Mansour A. Cancer care in Jordan. Hematol Oncol Stem Cell Ther. 2015 Jun;8(2):64-70. doi: 10.1016/j. hemonc.2015.02.001

9. Cancer trends in Lebanon \&projection to 2020. (https://www.syndicateofhospitals.org.lb/Content/uploads/SyndicateMagazinePdfs/82178-11.pdf).

10. 30 ooo people a year to get lung cancer in the Middle East by 2020. The National, 6 March 2017 (https://www.thenational.ae/ uae/30-0oo-people-a-year-to-get-lung-cancer- in-the-middle-east-by-2020-1.57481).

11. Maziak W. The global epidemic of water pipe smoking. Addict Behav. 2011;36:1-5.

12. Shamseddine A, Saleh A, Charafeddine M, Seoud M, Mukherji D, Temraz S, et al. Cancer trends in Lebanon: a review of incidence rates for the period of 2003-2008 and projections until 2018. Popul. Health Metrics. 2014;12(1):4. doi: 10.1186/1478-7954-12-4.

13. Danaei G, Vander Hoorn S, Lopez AD, Murray CJ, Ezzati M; Comparative Risk Assessment Collaborating Group (Cancers). Causes of cancer in the world: comparative risk assessment of nine behavioral and environmental risk factors. Lancet. 2005 Nov 19;366(9499):1784-93.

14. Wu S, Powers S, Zhu W, Hannun YA. Substantial contribution of extrinsic risk factors to cancer development. Nature. 2016;529(7584);43-47.

15. Charafeddine MA, Olson SH, Mukherji D, Temraz SN, Abou-Alfa GK, Shamseddine AI. Proportion of cancer in a Middle Eastern country attributable to established risk factors. BMC Cancer 2017;17(1):337. doi: 10.1186/s12885-017-3304-7.

16. El Bcheraoui C, Basulaiman M, Wilson S, Daoud F, Tuffaha M, AlMazroa MA, et al. Breast cancer screening in Saudi Arabia, free but almost no takers. PLoS One. 2015; 10(3): e0119051. doi: 10.1371/journal.pone.0119051.

17. World Health Organization. Cancer Control Programme. (http://www.who.int/cancer/en/).

18. Al-Jaber A, Al-Nasser L, El-Metwally A. Epidemiology of oral cancer in Arab countries. Saudi Med J. 2016 Mar;37(3):249-255 doi: 10.15537/smj.2016.3.11388

19. Saudi Health Council. Cancer Incidence Report, Saudi Arabia 2014. Riyadh: Saudi Health Council; 2017 (https://nhic.gov.sa/eServices/Documents/2014.pdf)

20. Rabah D, Arafa MA. Prostate cancer screening in a Saudi population: an explanatory trial study. Rabah D, Arafa MA. Prostate cancer screening in a Saudi population: an explanatory trial study. Prostate Cancer Prostatic Dis. 2010;13(2):191-4

21. Khatib O, Aljurf M. Cancer prevention and control in the Eastern Mediterranean Region: the need for a public health approach. Hematol Oncol Stem Cell Ther. 2008 Jan-Mar;1(1):44-52. 